\title{
基于氧化[3+2]环加成反应合成二氢苯并呋喃类天然产物
}

\author{
赵军 $a$ 肖 检*, 王雅雯 $a$ 彭 羽*,a,b
}

( ${ }^{a}$ 西南交通大学生命科学与工程学院 四川省天然药物仿生合成工程研究中心 成都 610031) $(b$ 伊犁师范大学化学与环境科学学院 新疆伊宁 835000)

\begin{abstract}
摘要 二氢苯并呋喃结构单元广泛存在于生物碱及萜类等多种天然产物中, 这些天然产物大多具有良好的生物活性和 药用价值. 因此, 近年来有关具有二氢苯并呋喃环骨架的天然产物全合成工作不断涌现. 综述了近十多年来氧化 $[3+2]$ 环加成反应在构建二氢苯并呋喃环骨架及各类天然产物全合成方面的应用进展.

关键词 氧化 $[3+2]$ 环加成; 二氢苯并呋喃; 天然产物; 全合成; 仿生合成
\end{abstract}

\section{Advances on the Synthesis of Natural Products with Dihydrobenzo- furan Skeleton via Oxidative [3+2] Cycloadditions}

\author{
Zhao, Jun ${ }^{a} \quad$ Xiao, Jian*,a Wang, Yawen ${ }^{a} \quad$ Peng, $\mathrm{Yu}^{*, a, b}$ \\ $\left({ }^{a}\right.$ Engineering Research Center of Biomimetic Synthesis of Natural Drugs of Sichuan Province, \\ School of Life Science and Engineering, Southwest Jiaotong University, Chengdu 610031) \\ $\left({ }^{b}\right.$ School of Chemistry and Environment Science, Yili Normal University, Yining, Xinjiang 835000)
}

\begin{abstract}
Dihydrobenzofuran structure units widely exist in a variety of natural products, such as alkaloids and terpenes. The total synthesis of natural products containing dihydrobenzofuran skeleton has thus emerged in recent years, because of their good biological activities and medicinal value. The application progress of oxidative $[3+2]$ cycloaddition in the construction of dihydrobenzofuran ring skeleton and the total synthesis of various natural products in recent ten years was reviewed. Keywords oxidative [3+2] cycloaddition; dihydrobenzofuran; natural product; total synthesis; biomimetic synthesis
\end{abstract}

自然界存在众多具有二氢苯并呋喃(Dihydrobenzofuran, DHB，图 1)结构单元的天然产物，它们大多具有 良好的药理活性. 例如表现出抗疮疾 ${ }^{[1]}$ 、抗炎和抗菌活 性 ${ }^{[2]}$ 的(+)-Decursivine (1)和(+)-Azonazine (2), 以及显 示出抗氧化、细胞保护特性和杀虫活性 ${ }^{[3]}$ 的(一)-Viminalin A (3)等. 这些活性天然产物在生命科学发展和药 物创制中也扮演着至关重要的角色.

2,3-二氢苯并呋喃的结构中包含一个与苯环稠合的 饱和五元氧杂环, 其氧原子与芳香体系相邻. 在过去的 几十年里, 有机合成化学家陆续报道了构建该结构单元 的方法. 例如苯酚烷基化 ( $O$-烷基键的形成)、过渡金属 催化的交叉偶联构建 $O$-芳基键、过渡金属介导的卡宾

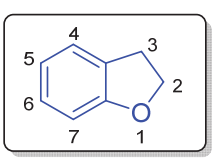

DHB<smiles>CC(=O)N1c2ccccc2[C@@]2(C)c3ccc4cc3OC(O4)[C@H]2N1C(C)=O</smiles>

(+)-Azonazine (2)

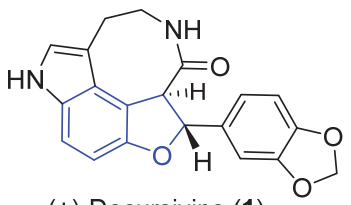

(+)-Decursivine (1)<smiles>COc1cc(O)c(C(=O)C=C(C)C)c2c1C1C[C@H](C(C)C)C3OC3[C@@]1(C)O2</smiles>

图 1 含苯并呋喃骨架的天然产物列举

Figure 1 Natural products with dihydrobenzofuran skeleton

* Corresponding authors. E-mail: xiaojian@swjtu.edu.cn; pengyu@swjtu.edu.cn

Received March 26, 2021; revised April 21, 2021; published online May 13, 2021.

Project supported by the National Natural Science Foundation of China (Nos. 21772078, 22071200), the Science and Technology Department of Sichuan Province (No. 2020JDRC0021) and the Fundamental Research Funds for the Central Universities (No. 2682020CX55).

国家自然科学基金(Nos. 21772078, 22071200)、四川省科技计划(No. 2020JDRC0021)和中央高校基本科研业务费专项资金(No. 2682020CX55)资助项 目. 
$\mathrm{C}-\mathrm{H}$ 插入、氧化 $[3+2]$ 环加成和重排反应等(Scheme $1)^{[4]}$, 这些方法各具特色. 本综述主要介绍氧化 $[3+2]$ 环 加成反应构建该结构单元及在各类天然产物全合成方 面的应用进展.

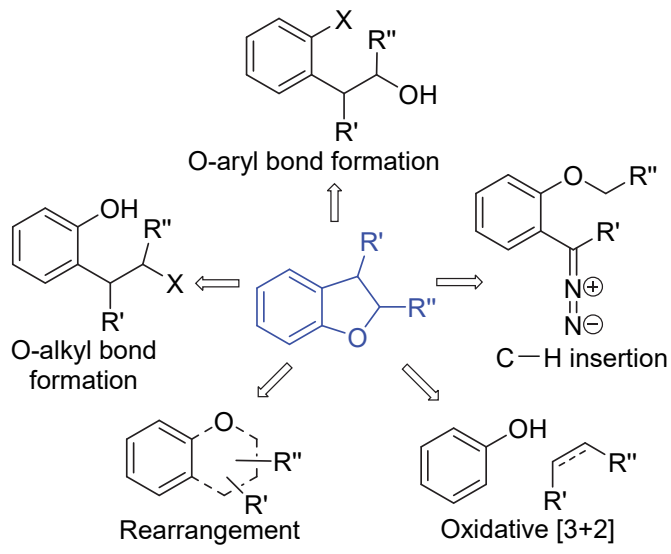

图式 1 呋喃环单元的构建方法列举

Scheme 1 Methods for construction of dihydrobenzofuran

苯酚和烯烃在氧化剂作用下发生环化反应，又称氧 化 $[3+2]$ 环加成反应(Scheme 2, a), 目前已报道的反应 类型有催化氧化环加成和计量氧化环加成两类 ${ }^{[5]}$. 鉴于 本文总结的全合成研究工作, 以三价碘为氧化剂来构建 2,3-二氢苯并呋喃环的例子居多, 在此主要介绍三价碘

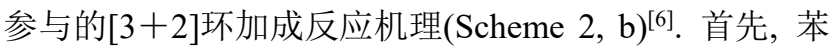
酚 $\mathbf{A}$ 中的氧原子进攻 $\mathrm{PhI}(\mathrm{OAc})_{2}$ 的碘中心, 生成三价碘 中间体 B. 此中间体解离出一分子 $\mathrm{AcOH}$ 和 $\mathrm{PhI}$ 后, 生

(a)

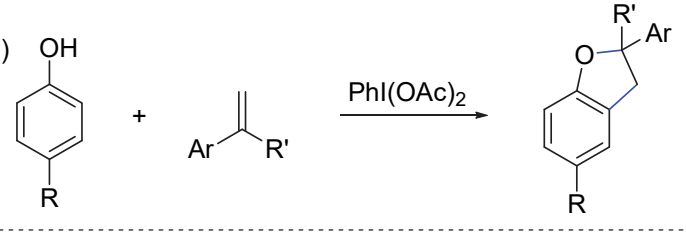

(b)<smiles>[R]c1ccc(O)cc1</smiles>

A

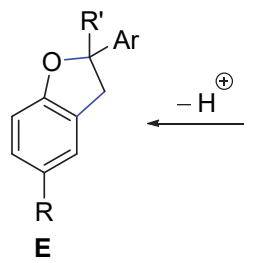

B

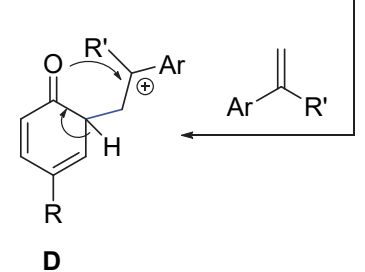

图式 2 三价碘参与的氧化 $[3+2]$ 环加成反应的机理 Scheme 2 Mechanism of oxidative [3+2] cycloaddition reaction with trivalent iodine
成碳正离子中间体 $\mathbf{C}$. 随后，中间体 $\mathbf{C}$ 与富电子烯烃发 生亲电加成反应生成碳正离子中间体 D. 最后，中间体 D 再发生环化，从而生成二氢苯并呋喃类产物 $\mathbf{E}$.

随着氧化 $[3+2]$ 环加成反应研究的不断深入，近年 来，该反应也被应用于多种天然产物的全合成之中[7]. 因此，很有必要对该反应在天然产物全合成领域的进展 进行总结. 本文将含有二氢苯并呋喃环骨架的天然产物 分为生物碱、萜类、木脂素和黄酮等四类，对氧化[3+ 2]环加成反应在这四类天然产物中的合成应用进展分 别进行了论述.

\section{1 氧化[3+2]环加成反应在生物碱合成中的应 用}

1991 年, Fenical 小组 ${ }^{[8 a]}$ 从海鞘中分离得到具有抗有 丝分裂作用的生物碱类天然产物 Diazonamide A (7), 由 于其具有强效的抗肿瘤活性，亦可用作抗癌药物研究的 先导化合物. 它的结构含有一个杂环组成的十二元大 环, 包括吲哚单元、二氢吲哚环和噁唑-噁唑相联结构, 以及含氢化苯并呋喃环的一个十二元内酰胺大环. 因 此，该分子的全合成十分具有挑战性. 2003 年, Harran 课 题组 ${ }^{[8 b]}$ 基于该分子的生源合成假说，以 19 步完成该天 然产物的全合成(Scheme 3). 他们以外消旋的 7-澳代色 氨酸甲酯盐酸盐(4)为起始原料, 经酰胺化等 4 步反应得 到噁坐化合物 5. 然后在三价碘试剂 $\mathrm{PhI}(\mathrm{OAc})_{2}$ 的氧化 下发生分子内氧化 $[3+2]$ 环加成反应，以 $25 \%$ 和 $8 \%$ 的 产率分别得到氢化苯并呋喃化合物 6 和 6 . 化合物 6 经 后续转化从而实现天然产物(一)-Diazonamide A 的全合 成. 虽然总路线较为圥长, 但开创了氧化 $[3+2]$ 环化反 应在复杂生物碱类天然产物全合成中应用的先例，具有 重要意义

与(一)-Diazonamide A 结构相似, 天然产物 $(+)-$ Azonazine (2)核心骨架也含有氢化苯并呋喃吲哚啉四环 结构. 另外还有一个二酮哌嗪结构, 两个片段通过一个 十元桥环连接. 该天然产物是由 Crews 小组 ${ }^{[2]}$ 于 2010 年 从夏威夷海洋沉积物的衍生曲霉属真菌中分离的一类 生物碱，研究发现其具有一定的抗炎活性. 2013 年, 姚 祝军课题组从生源合成角度出发, 完成其对映体 (一)-Azonazine (2)的首次全合成(Scheme 4), 并对天然 产物的绝对立体化学进行了修正 ${ }^{[9]}$. 他们以 $D$-酪氨酸衍 生物 8 为起始原料, 经三甲基化反应和 2-溴-1-乙基吡啶 四氟硼酸盐(BEP)促进的偶联等多步转化生成环化前体 12. 随后在三氟乙醇为溶剂, $\mathrm{PhI}(\mathrm{OAc})_{2}$ 为氧化剂的条件 下发生分子内 $[3+2]$ 环加成反应，构建氢化苯并呋喃吲 哚啉骨架化合物 13. 再经过水解、还原、乙酰化等 5 步 反应，最终完成了(一)-Azonazine (2)的仿生合成. 
<smiles>CC(=O)O[C@H](Cc1c[nH]c2c(Br)cccc12)N[C@H](Cl)Cc1ccc(O)cc1</smiles>

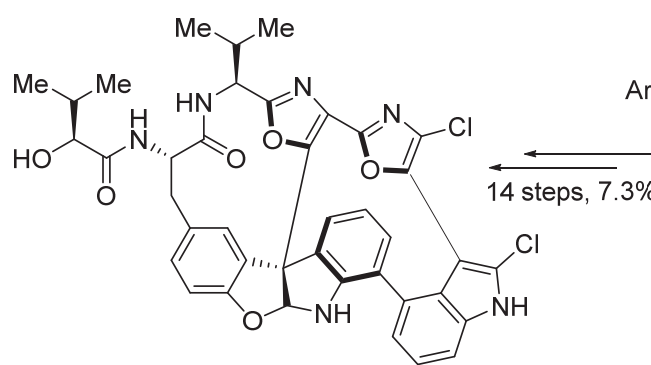

(-)-Diazonamide A (7)

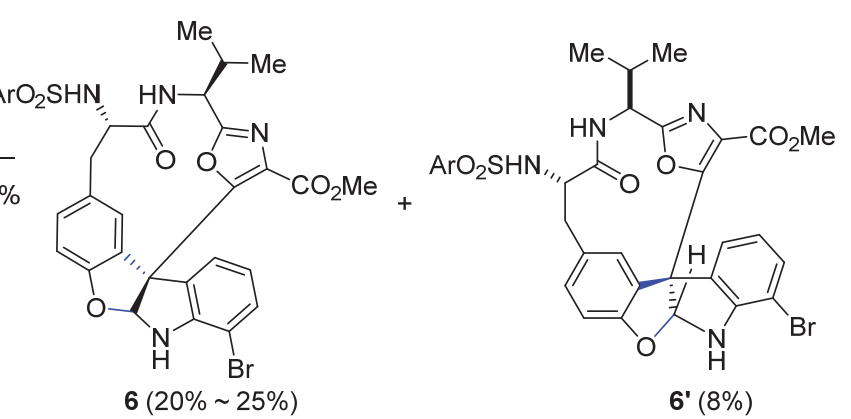

图式 3 Harran 小组对(一)-Diazonamide A 的全合成

Scheme 3 Total synthesis of ( - -Diazonamide A by Harran's group

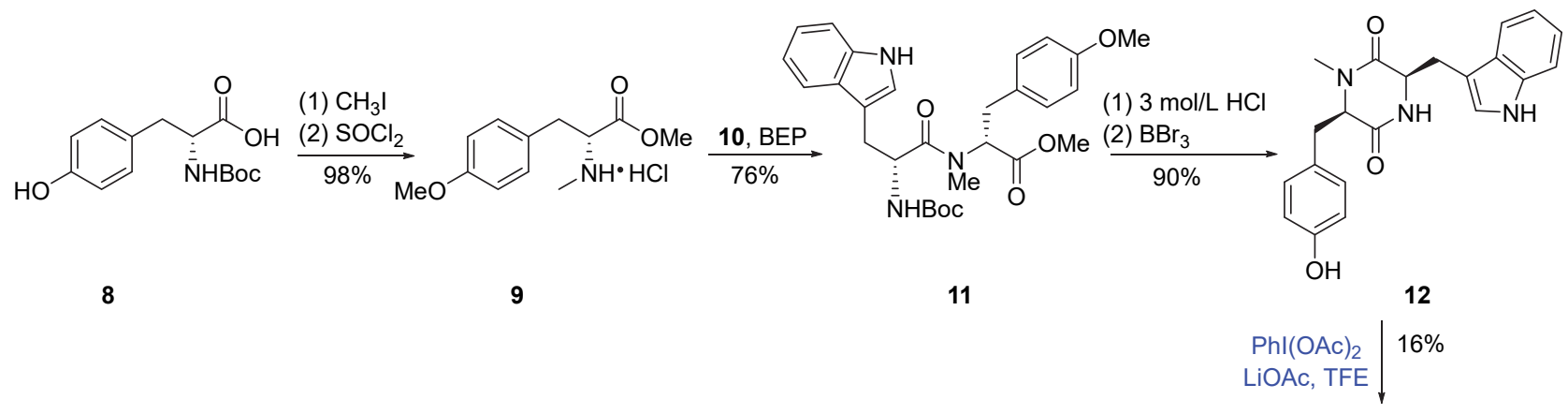
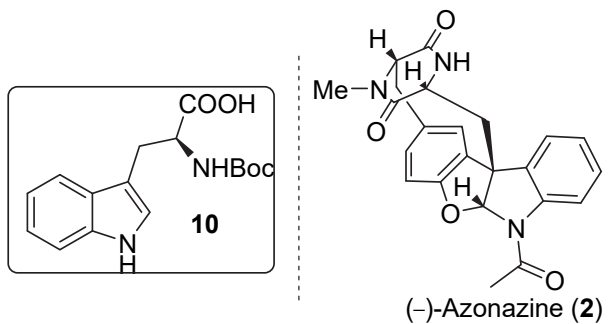

(1) $\mathrm{HOAc}, \mu \mathrm{W}$ (2) $\mathrm{NaBH}_{4}$

(3) $\mathrm{Tf}_{2} \mathrm{O}, \mathrm{Et}_{3} \mathrm{~N}$

(4) $\mathrm{H}_{2}, \mathrm{Pd}(\mathrm{OH})_{2} / \mathrm{C}$ 4 steps, $24 \%$

14

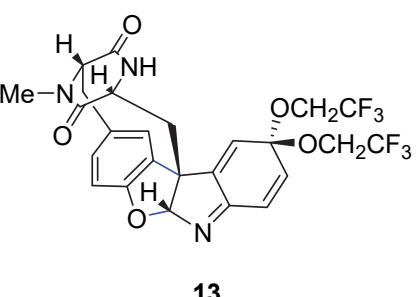

13

图式 4 姚祝军小组对(一)-Azonazine 的全合成

Scheme 4 Total synthesis of (-)-Azonazine by Yao's group

1999 年, Colegate 小组 ${ }^{10 a]}$ 从金丝雀曧草中分离得 到呋喃双吲哚生物碱天然产物 Phalarine, 其相关生物活 性尚未明确. 2014 年, Vincent 课题组 ${ }^{[10 b]}$ 报道以苯酚 16 和 $N$-乙酰基吲哚 15 之间的氧化偶联反应为关键步骤, 选择性合成了苯并呋喃[3,2- $b$ 吲哚啉骨架化合物 17. 该 反应以苯酚与 $N$-乙酰基吲哚为原料, 在室温下以 $2,3-$ 二 氯-5,6-二氧基对苯醌(DDQ)为氧化剂和 $\mathrm{FeCl}_{3}$ 为催化剂 的条件下, 选择性地生成苯并呋喃[3,2-b $b$ 吲哚啉骨架 17. 该方法为 Phalarine (18) 的全合成提供了启发 (Scheme 5).

2019 年, 贾彦兴课题组 ${ }^{[11]}$ 以氧化 $[3+2]$ 环化反应为
关键，经过巧妙设计，仅用 8 步反应就完成了 Phalarine (18)的全合成(Scheme 6). 这也是迄今为止合成该分子 的最短路线, 极大地提高了该天然产物的合成效率. 他 们以商业可得的色胺 19 为起始原料, 经酰胺化、氮保护 等 3 步反应得到咔啉化合物 $\mathbf{2 0}$. 随后, 20 与苯酚片段 $\mathbf{2 1}$ 在六氟异丙醇为溶剂、 $\mathrm{PhI}(\mathrm{OAc})_{2}$ 作氧化剂和氟硼酸作 催化剂的条件下, 以 $30 \%$ 的产率得到苯并呋喃吲哚啉骨 架化合物 22. 经 Suzuki 偶联、红铝还原等 4 步反应，最 终以 5.5\%的总收率实现 Phalarine (18)的全合成，为该天 然产物后续的生物活性研究提供保障. 
<smiles>[R]c1cn(C(C)=O)c2ccccc12</smiles>

15<smiles>[R]c1cccc(O)c1</smiles>

16<smiles></smiles>

17<smiles>COc1cc(OC)c2[nH]cc(CN(C)C)c2c1[C@H]1Nc2ccccc2[C@H]1C(C)(C)C</smiles>

Phalarine (18)

图式 5 Vincent 小组对 Phalarine 骨架的合成研究

Scheme 5 Synthetic studies of Phalarine skeleton by Vincent's group<smiles>NCCc1c[nH]c2ccccc12</smiles>

Tryptamine (19)
(1) $\left(\mathrm{CH}_{2} \mathrm{O}\right)_{n}$

(2) $\mathrm{ClCO}_{2} \mathrm{Me}$

(3) $\mathrm{BzCl}, \mathrm{NaH}$

3 steps, $76 \%$<smiles>COc1cc(OC)c2[nH]cc(CN(C)C)c2c1[C@@]12CC(C)(C)[C@@H]1c1ccccc1N2</smiles><smiles>COc1cc(O)cc(Br)c1[N+](=O)[O-]</smiles>

$30 \%$<smiles>COc1cc(OC)c2[nH]ccc2c1[C@H]1Nc2ccccc2N1C(C)C</smiles>

(1) $\mathrm{P}(\mathrm{OEt})_{3}$ (2) Red-Al 2 steps, $38 \%$

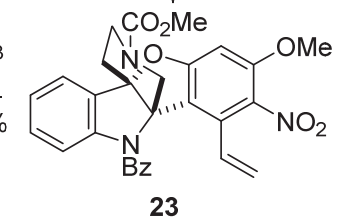

图式 6 贾彦兴小组对 Phalarine 的全合成

Scheme 6 Total synthesis of Phalarine by Jia's group

1952 年, Snyder 小组 ${ }^{[12 \mathrm{a}]}$ 从野花夹竹桃(Haplophyton cimicidum) 中分离得到吲哚生物碱 Haplophytine (33). 活 性研究表明该天然产物分子具有广谱杀虫活性. 结构 上, 它具有极其复杂的多环骨架, 可看作是由两个片段
组合而成: 左侧为一个桥环酮的结构; 右侧为天然生物 碱 Aspidophytine, 有十个环和六个立体中心(其中五个 为季碳中心). 2009 年, Nicolaou 课题组 ${ }^{[12 b]}$ 通过汇聚合成 策略完成了该分子的全合成工作(Scheme 7). 关键步骤

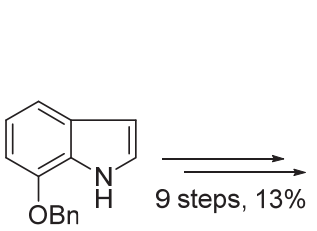

25

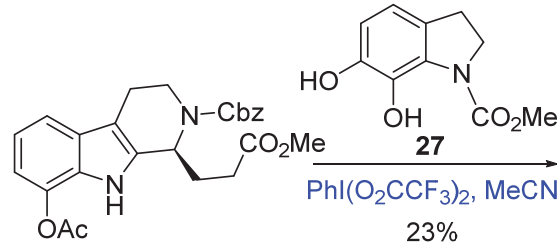

26

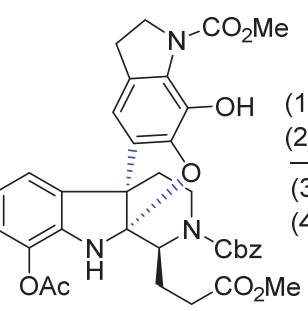

28
(1) $\mathrm{CH}_{3} \mathrm{I}, \mathrm{Cs}_{2} \mathrm{CO}_{3}$ (2) $\mathrm{K}_{2} \mathrm{CO}_{3}, \mathrm{MeOH}$

(3) $\mathrm{BnBr}, \mathrm{Cs}_{2} \mathrm{CO}_{3}$

(4) $\mathrm{CH}_{3} \mathrm{l}, \mathrm{Cs}_{2} \mathrm{CO}_{3}$ 4 steps, $34 \%$ OBn

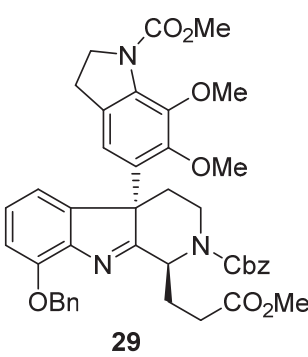

(1) $\mathrm{LiOH}$

(2) $(\mathrm{COCl})_{2} 3$ steps, $60 \%$

(3) $i-\mathrm{Pr}_{2} \mathrm{NEt}$
31

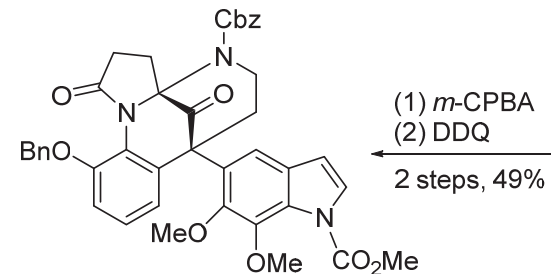

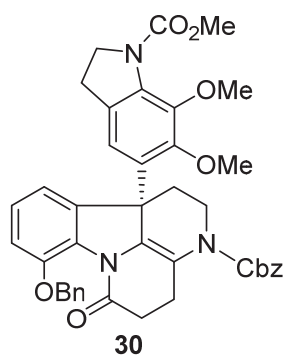

图式 7 Nicolaou 小组对 Haplophytine 的全合成

Scheme 7 Total synthesis of Haplophytine by Nicolaou's group 
包括高价碘为氧化剂的 $[3+2]$ 环加成反应及 Suzuki 偶联 等反应. 他们从 7-芐氧基吲哚 25 出发, 经过氢化还原等 9 步反应得到四氢 $\beta$-咔啉中间体化合物 26. 化合物 26 再与二酚化合物 27 在高价碘试剂 $\mathrm{PhI}\left(\mathrm{O}_{2} \mathrm{CCF}_{3}\right)_{2}$ 为氧化 剂条件下成功构建了呋喃环, 以 $23 \%$ 的产率得到了六环 化合物 28. 酯基水解后, 再构建内六元酰胺得到化合物 30, 然后经氧化重排得到目标吲哚化合物 31. 它与烯基 碘化合物 32 经 Suzuki 偶联等 13 步反应, 最终成功实现 了 Haplophytine (33) 的全合成工作.

2002 年, Fong 小组 ${ }^{[1]}$ 从天南星科植物爬树龙的枝干 和树叶中分离出吲哚生物碱类天然产物 $(+)$-Decursivine (1), 该分子表现出抗㾏疾等活性. 该天然产物具 有独特的四环骨架, 含有呋喃环、吲哚和八元内酰胺. 2011 年, 受该天然产物的生源合成启发, 李超忠课题 组 ${ }^{[13]}$ 仅用 10 步反应实现了 $(+)$-Decursivine (1) 的首次不 对称全合成(Scheme 8). 他们从廉价易得的 $D$-色氨酸衍 生物 34 出发, 经酸胺缩合等多步反应得到环化前体 38 .
随后, 38 在高价碘试剂的氧化下发生分子内氧化 $[3+2]$ 环加成反应，高度非对映选择性地构建了二氢苯并呋喃 和八元内酰胺两个环系，以 $60 \%$ 的产率得到化合物 39 . 最后经水解脱羧, 以 $16.7 \%$ 的总产率实现了 $(+)$-Decursivine 的仿生合成.

基于类似的氧化 $[3+2]$ 环加成合成策略设计，2016 年, 夏成峰课题组 ${ }^{[14]}$ 报道了铁催化的氧化自由基偶联 反应，并以 11 步高效完成了 $(+)$-Decursivine (1)的全合 成. 他们从易制备的 $D$-色氨酸衍生物 40 出发, 经氧化、 羟基保护和引入亚甲基二氧基肉桂酰胺片段等反应得 到环化前体化合物 41, 随后以六氟异丙醇为溶剂, 经 $\mathrm{FeCl}_{3}$ 催化和 2,3-二氯-5,6-二氰基对苯醌(DDQ)氧化的偶 联反应, 高度非对映选择性地得到同时含二氢苯并呋喃 环和八元内酰胺的吲哚化合物 42. 最后, 经脱氮保护基 和脱羧等 5 步反应, 实现了 $(+)$-Decursivine 分子的全合 成(Scheme 9).

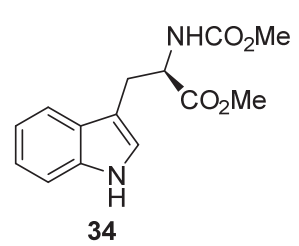

(1) $\mathrm{Pb}(\mathrm{OAc})_{4}$ (2) $\mathrm{Zn}$ (3) TBDPSCI (4) Nal, TMSCl 4 steps, $47 \%$

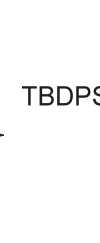<smiles>COc1ccc2[nH]cc(CC(C)N)c2c1</smiles>

35
(1) $36, \mathrm{EDC}$ (2) $\mathrm{Boc}_{2} \mathrm{O}$<smiles>CC(C)(C)OC(=O)NC(=O)C=Cc1ccc2c(c1)OCO2</smiles>

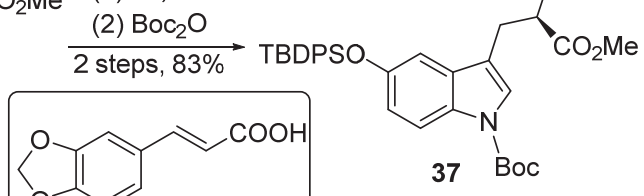

36

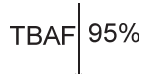<smiles>O=C1NCCc2c[nH]c3ccc4c(c23)C1C(c1ccc2c(c1)OCO2)O4</smiles>

(+)-Decursivine (1)

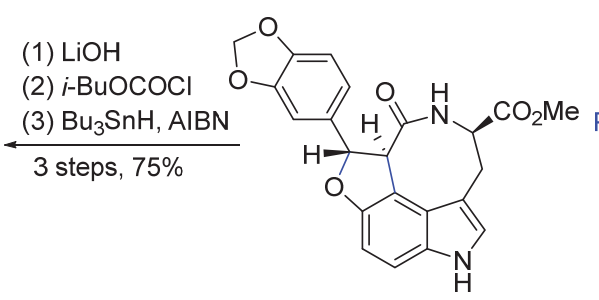

39

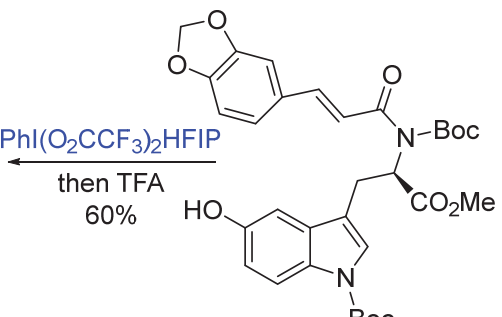

38

图式 8 李超忠小组对 $(+)$-Decursivine 的全合成

Scheme 8 Total synthesis of (+)-Decursivine by Li's group

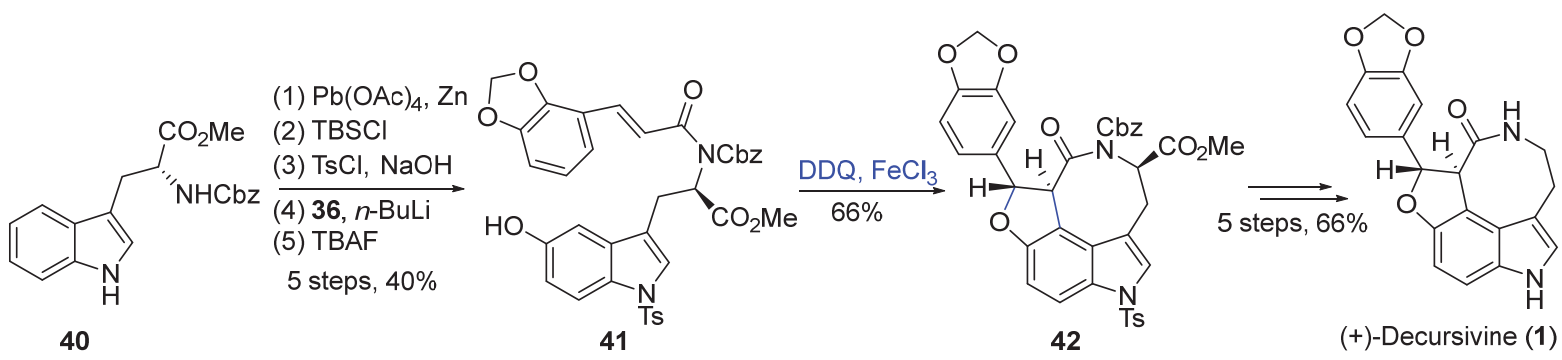

图式 9 夏成峰小组对 $(+)$-Decursivine 的全合成

Scheme 9 Total synthesis of ( + -)-Decursivine by Xia's group 
1985 年, Sato 小组 ${ }^{[15 a]}$ 从红花种子(Carthamus tinctorius L.) 中分离得到具有抗菌活性的吲哚生物碱 $( \pm)-$ Serotobenine (48), 其结构与 (+)-Decursivine (1)类似, 推测它们可能有共同的生源合成途径. 受此启发, 2016 年, 夏成峰课题组 ${ }^{[15 b]}$ 完成了 $( \pm)$-Serotobenine 全合成 (Scheme 10). 他们以商业可得的 5-着色胺盐酸盐 43 为 起始原料, 经叔丁基二甲基硅烷基(TBS)保护后, 再用 $\mathrm{TsCl}$ 进一步保护吲哚环, 得到环化前体 44. 然后在六氟 异丙醇溶剂中以 $\mathrm{DDQ}$ 为氧化剂, 在 $\mathrm{FeCl}_{3}$ 的催化下与烯 烃 45 发生氧化偶联, 以 $46 \%$ 的收率得到吲哚呋喃环化
合物 46, 再在三苯基膦条件下还原叠氮的同时构建了 八元内酰胺 47. 最后脱掉磺酰基和茮基保护基，从而以 $21.7 \%$ 的总收率高效合成了 $( \pm)$-Serotobenine.

\section{2 氧化 $[3+2]$ 环加成反应在萜类合成中的应用}

Merochlorin B (55) 是从链霉菌沉积物中分离得到 的一种萜类天然产物 [16a], 活性研究显示它对耐甲氧西 林金黄色葡萄球菌引起的感染具有良好活性. 2014 年, Trauner 课题组 ${ }^{[16 b]}$ 从生源合成角度出发, 以 8 步反应高 效完成了该天然产物的全合成(Scheme 11). 他们以商业

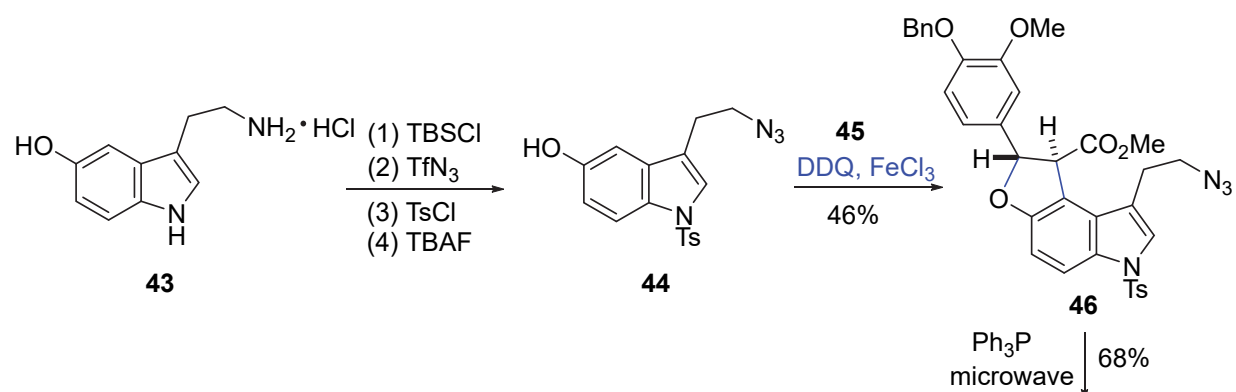
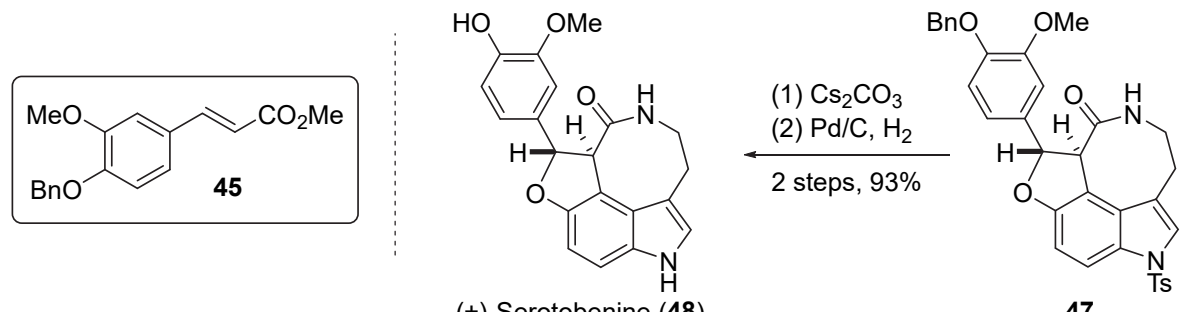

( \pm )-Serotobenine (48)

47

图式 10 夏成峰小组对 $( \pm)$-Serotobenine 的全合成 Scheme 10 Total synthesis of $( \pm)$-Serotobenine by Xia's group<smiles>COc1cc(CC(C)=O)cc(OC)c1</smiles>

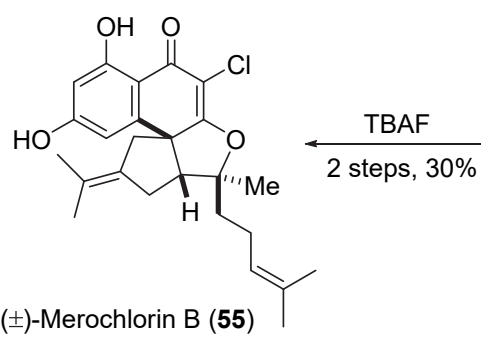<smiles>CC(C)=CCC[C@]1(C)OC2=C(Cl)C(=O)c3c(O)cc(OC(C)C)cc3[C@@]23CC(C)=C(C)C[C@@H]13</smiles>

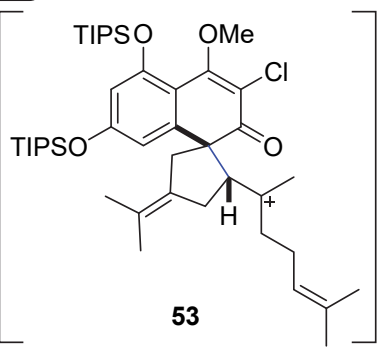

图式 11 Trauner 小组对 $( \pm)$-Merochlorin B 的全合成

Scheme 11 Total synthesis of $( \pm)$-Merochlorin B by Trauner's group 
可得的芳基乙酸甲酯 49 为起始原料，经傅克乙酰化、 Dieckmann 缩合、硅基保护、氯代和脱甲基共 5 步反应 得到苯酚化合物 50. 通过烷基化反应引入脂肪链 51, 得 到环化前体 52. 它在三价碘试剂亚碘酰苯(PhIO)的氧化 下发生分子内氧化 $[3+2]$ 环加成反应构建 $[5,5]$ 并环 $\mathbf{5 4}$, 最后脱硅保护基从而实现 Merochlorin B (55)的全合成.

Hypocrolide $A(60)$ 是从葡萄孢代谢产物分离得到的 一种倍半萜类天然产物 ${ }^{[17 a]}$, 其对枯草芽孢杆菌和腐霉 具有显著的抑制活性, 另外对人类肿瘤细胞也显示出高 细胞毒性. 因此, 作为抗肿瘤药物研究的先导化合物, 通过化学合成途径解决它的来源问题有其必要性. 该天 然产物具有六环稠合体系, 包含两个季碳中心在内的六 个立体中心. 该分子的结构独特性和较好的生物活性引 起了许多研究者的兴趣. 2016 年, 李闯创课题组 ${ }^{[17 b]}$ 从生 源合成角度出发, 以 12 步的高效路线完成了 Hypocrolide $\mathrm{A}$ 的不对称合成(Scheme 12). 他们以 4,4-二甲基环 己-2-烯酮 56 为起始原料, 经环氧化、Diels-Alder 反应 等 8 步反应得到双烯化合物 57. 随后, 它与香豆素衍生 物 58 在硝酸铈铵和醋酸铜条件下发生氧化 $[3+2]$ 环加 成反应, 以 $18 \%$ 的产率得到呋喃环骨架化合物 59. 最
后, 经还原、氧化和脱保护等 3 步反应, 实现了 Hypocrolide A 的合成.

2018 年, 谢志翔课题组 ${ }^{[18]}$ 从生源合成角度出发, 高 效完成了 Callistrilones 系列天然产物的全合成(Scheme 13). 他们以易制备的间三苯酚衍生物 61 和商业可得的 $\alpha$-水芹烯 62 为起始原料, 在硝酸铈铵为氧化剂的条件 下发生分子间的氧化 $[3+2]$ 环加成反应, 得到二氢苯并 呋喃 63 和 $63^{\prime}$. 它们随后发生迈克尔加成反应和分子内 亲核加成反应等多步转化，从而实现了 Callistrilone $\mathrm{E}$ 和 $\mathrm{B}$ 的仿生合成.

2019 年, Dethe 课题组 ${ }^{[19]}$ 同样采用仿生合成策略, 高效完成了 Viminalins A、B、H、I 和 N 的全合成(Scheme 14). 他们以商业可得的间苯三酚 67 为起始原料, 经酚 差基甲基化和 Friedel-Crafts 反应得到二酚片段 68. 它与 $\alpha$-水芹烯 62 在 $\mathrm{AgCO}_{3}$ 为氧化剂的条件下发生高度区域 选择性和非对映选择性氧化 $[3+2]$ 环加成反应, 分别以 $61 \%$ 和 $62 \%$ 的产率得到了天然产物(一)-Viminalins $\mathrm{H}$ 和 I. 将这两个天然产物再分别经乙酰化、环氧化等 4 步反 应，以 $70 \%$ 和 $72 \%$ 的产率得到天然产物(一)-Viminalins $\mathrm{A}$ 和 $\mathrm{B}$.

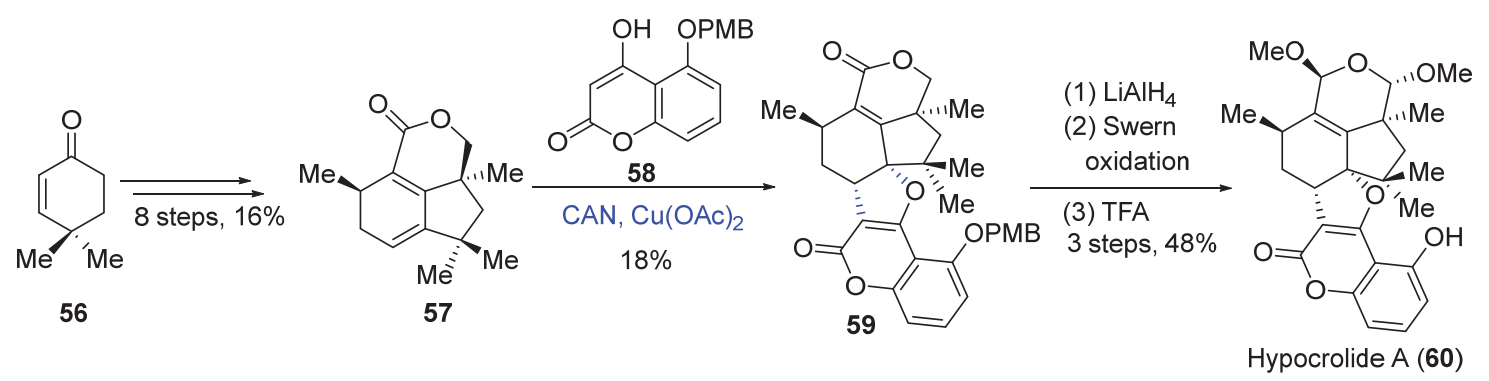

图式 12 李闾创小组对 Hypocrolide A 的全合成

Scheme 12 Total synthesis of Hypocrolide A by Li's group

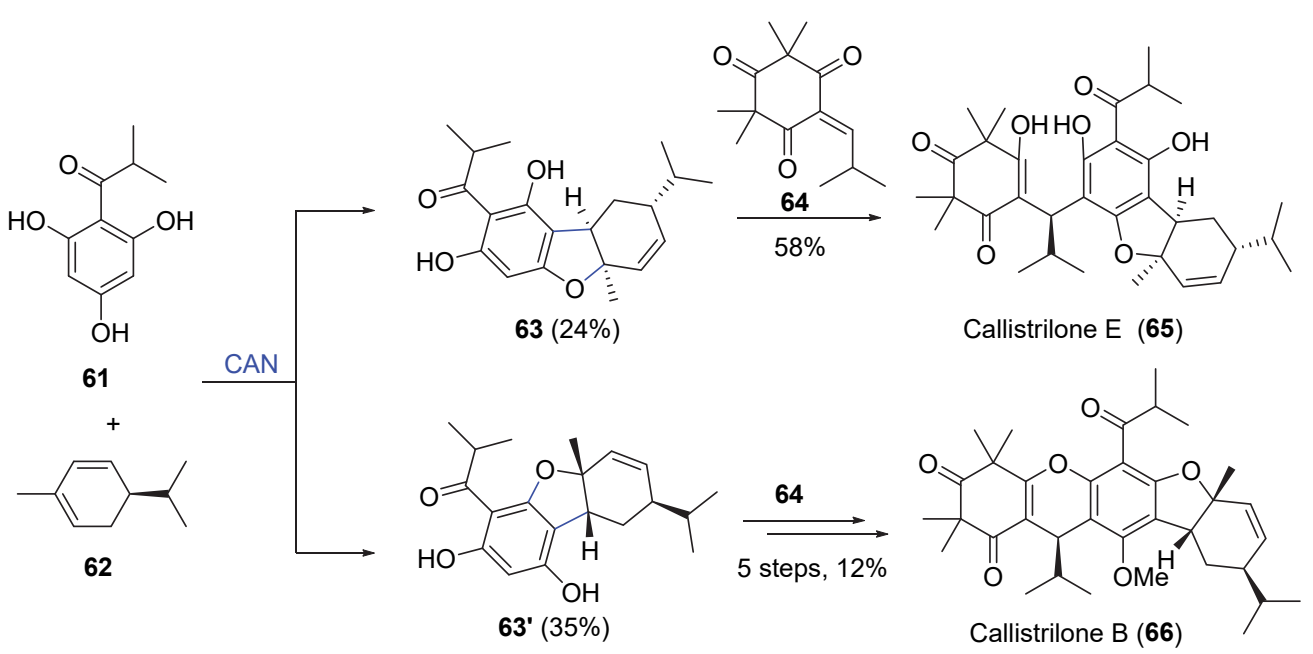

图式 13 谢志翔小组对 Callistrilones $\mathrm{A} \sim \mathrm{E}$ 的合成

Scheme 13 Total synthesis of Callistrilones A $\sim$ E by Xie's group 


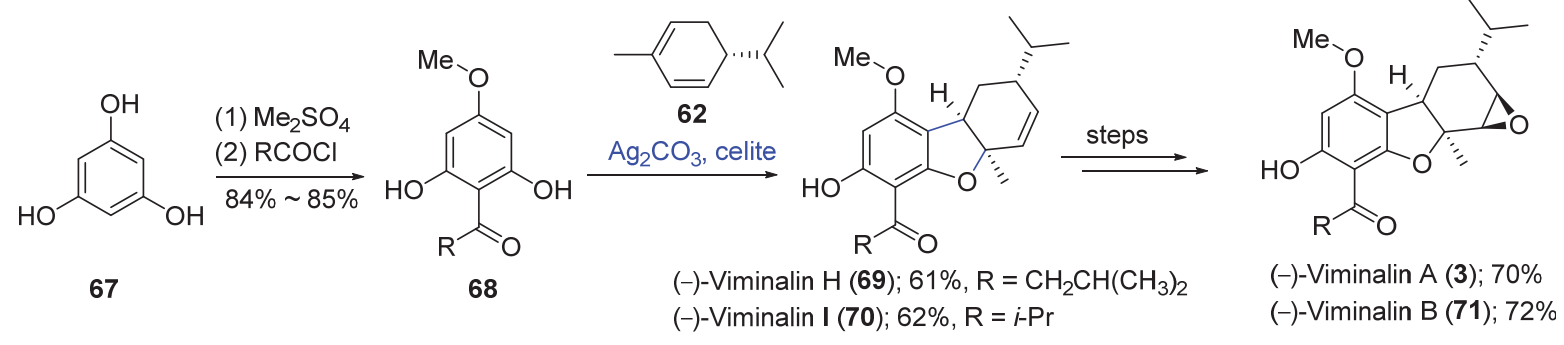

图式 14 Dethe 小组对 Viminalins A、B、H 和 I 的合成

Scheme 14 Total synthesis of Viminalins A, B, H and I by Dethe's group

\section{3 氧化 [3+2]环加成反应在木脂素合成中的应} 用

白藜芦醇(72)及其类似物是药物开发中的一类重要 化合物, 近年来受到越来越多的关注. 白藜芦醇 $(E)$-脱 氢二聚体[Resveratrol $(E)$-dehydrodimer, 73] 是 Pryce 小 组 ${ }^{[20 a]} 1977$ 年从葡萄藤中分离得到的多酚类天然产 物, 它与白藜芦醇低聚物 $\varepsilon$-葡萄素 $(\varepsilon$-viniferin, 74)活性 相似, 两者均具有对人体淋巴母细胞的细胞毒性、抗微 生物和抗氧化等活性. 2004 年, Sako 课题组 ${ }^{[20 b]}$ 以氧化 $[3+2]$ 环加成反应高效完成了白藜芦醇 $(E)$-脱氢二聚体 73 的合成工作 (Scheme 15). 反应以 $\mathrm{AgOAc}$ 为氧化剂, 在无水 $\mathrm{MeOH}$ 中加热 $1 \mathrm{~h}$, 最终以 $97 \%$ 的收率实现二聚 体 73 的合成. 同时, 从 $\varepsilon$-Viniferin (74)出发, 采用相同 的反应条件可完成 $\varepsilon$-Viniferin 二聚体 75 的合成.

肉豆冦作为天然香料的同时, 也是一种补胃祛风的 中药; 另外, 其对链球菌具有抗菌活性, 故也可作为用 于预防龊齿的药物. 脱氢二异丁香酚 (Dehydrodiisoeugenol, 77)和 Fragnasols $\mathrm{A} \sim \mathrm{C}(\mathbf{7 8} \sim \mathbf{8 0})$ 都是从该类
植物中分离得到的具有良好活性的新木脂烷类天然产 物 ${ }^{[21 a-21 b]} .2000$ 年, Antus 课题组 ${ }^{[21 c]}$ 设计了简洁高效的路 线，完成了这四种新木脂素的全合成(Scheme 16). 他们 以商业可得的异丁香酚 76 为起始原料, 在二氯甲烷溶 剂中, 以 $\mathrm{PhI}(\mathrm{OAc})_{2}$ 为氧化剂进行氧化 $[3+2]$ 环加成反 应得到脱氢二异丁香酚 77. 随后再以 77 为关键中间体 化合物, 通过后续官能团转化从而实现了 Fragnasols $\mathrm{A} \sim \mathrm{C}$ 分子的合成.

木兰科植物渐尖木兰(Magnolia acuminata L.)具有

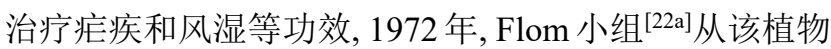
中分离得到具有二氢苯并呋喃结构的天然产物 Acuminatin (83). 2013 年, 王英基课题组 ${ }^{[22 b]}$ 采用氧化 $[3+2]$ 环加成反应为关键反应, 实现了其合成(Scheme 17). 他们以硝酸铈铵为氧化剂, 对烯基酚化合物 81 经 过自身氧化二聚构建二氢苯并呋喃环, 从而实现天然产 物(土)-Licarin A (82)的合成，再经酚羟基甲基化反应合 成 $( \pm)$-Acuminatin (83). 同时他们发现硝酸铈铵的浓度 和反应时间控制是影响该关键反应的重要因素.
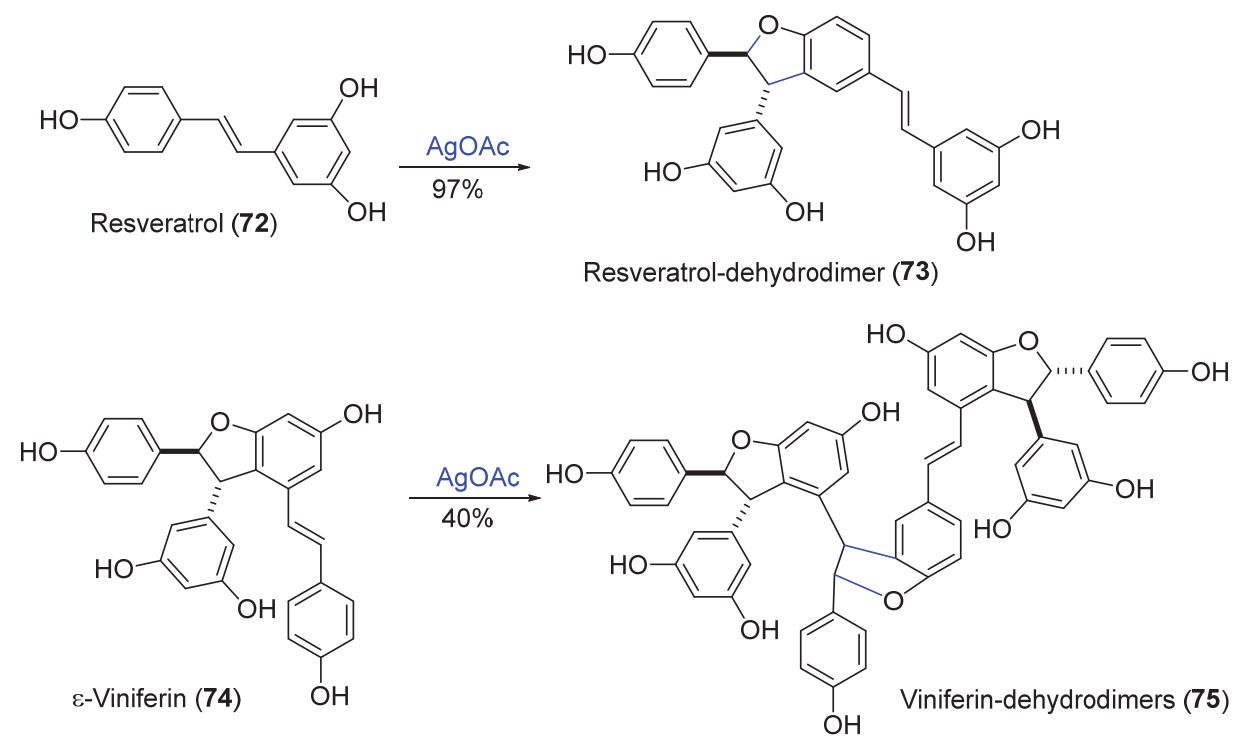

图式 15 Sako 小组对 Resveratrol 和 $\varepsilon$-Viniferin 二聚体的全合成

Scheme 15 Total synthesis of dimer of Resveratrol and $\varepsilon$-Viniferin by Sako's group 


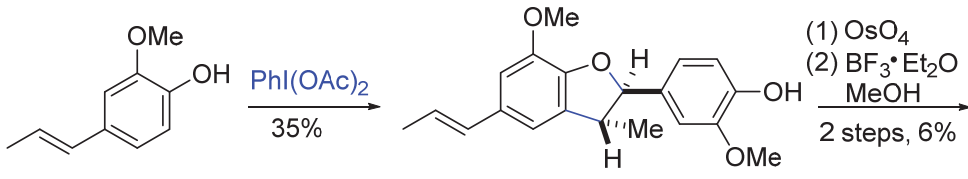

76<smiles>COc1cc([C@H]2Oc3c(OC)cc(CCO)cc3[C@H]2C)ccc1O</smiles>

Fragnasol B (79)<smiles>COc1cc(C2Oc3c(OC)cc(C(C)O)cc3C2[N+](=O)[O-])ccc1O</smiles>

Fragnasol A (78)

图式 16 Antus 小组对 Franasols $A \sim C$ 和 Dehydrodiisoeugenol 的全合成

Scheme 16 Total synthesis of Franasols A $\sim \mathrm{C}$ and Dehydrodiisoeugenol by Antus's group<smiles>C/C=C/c1ccc(O)c(OC)c1</smiles>

图式 17 王英基小组对 $( \pm)$-Licarin $\mathrm{A}$ 和( $( \pm)$-Acuminatin 的合成

Scheme 17 Total synthesis of $( \pm)$-Licarin A and $( \pm)$-Acuminatin by Wang's group

上述反应大多以 $\mathrm{PhI}(\mathrm{OAc})_{2}$ 等常见氧化剂来构建二 和富电子苯乙烯之间的氧化 $[3+2]$ 环加成反应, 并提出 氢苯并呋喃结构单元. 与此同时, 新方法也在不断地发 了该反应的机理 (Scheme 18). 金属盐 $\mathrm{Ru}(\mathrm{bpz})_{3}\left(\mathrm{PF}_{6}\right)_{2}$ 与 展. 2014 年, Yoon 课题组 ${ }^{[23]}$ 报道了光催化苯酚类化合物 $\quad\left(\mathrm{NH}_{4}\right)_{2} \mathrm{~S}_{2} \mathrm{O}_{8}$ 发生配阴离子交换生成 $\mathrm{Ru}(\mathrm{bpz})_{3}\left(\mathrm{~S}_{2} \mathrm{O}_{8}\right)_{2}$, 该

(a)<smiles>C=CCc1cc(OC)ccc1O</smiles><smiles>C/C=C/[14c]1ccc(O[R5](=O)(=O)c2ccccc2)cc1</smiles>

visible light
catalyst

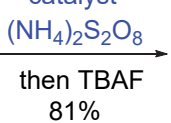

85
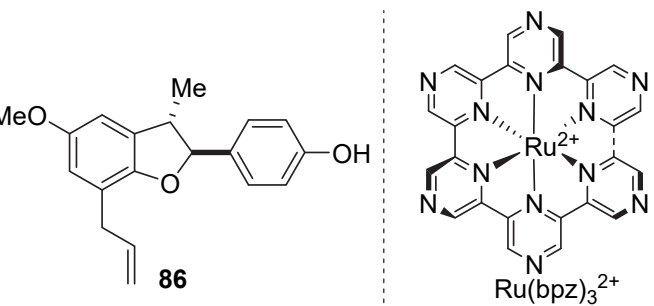

visible light catalyst

(b)

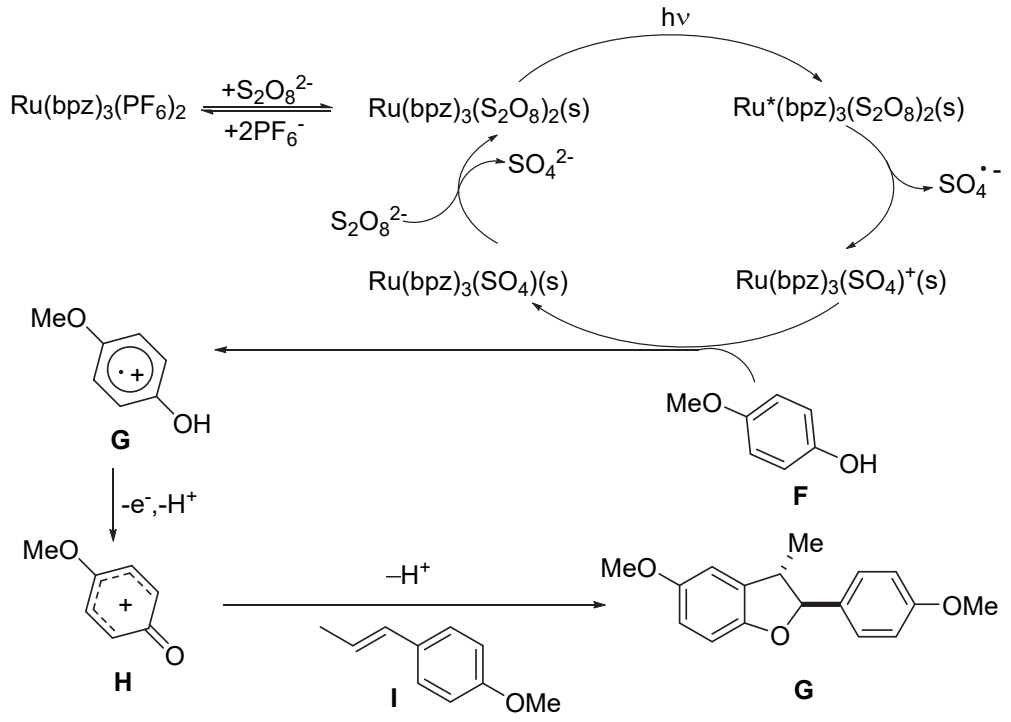

图式 18 Yoon 小组对新木脂素类天然产物的合成

Scheme 18 Synthesis of new natural products of lignans by Yoon's group 
盐在光照条件下激发, 经氧化淬灭生成 $\mathrm{Ru}(\mathrm{bpz})_{3}{ }^{3+}$. 它 与苯酚 $\mathbf{F}$ 作用生成正离子自由基 $\mathbf{G}$, 进一步氧化后生成 苯鎓离子 $\mathbf{H}, \mathbf{H}$ 再与富电子烯烃 $\mathbf{I}$ 反应生成目标化合物. 其中过硫酸铵作终端氧化剂, 反应过程中生成无害且易 于分离的无机副产物, 且该方法适用于多种富电子的苯 酚、多环苯酚和苯乙烯类化合物的环加成. 例如 4-甲氧 基苯酚衍生物 84 和烯烃 85 在光催化和过硫酸铵氧化条 件下构建二氢苯并呋喃骨架, 再经四丁基氟化铵脱硅保 护基，从而实现新木酯素类天然产物 86 的合成.

2014 年, 刘强课题组 ${ }^{[24]}$ 以介孔石墨氮化碳作为生 物催化剂, 光照条件下合成了 Resveratrol 二聚体 (Scheme 19). 他们以乙腈溶剂, 在 $m p g-C_{3} \mathrm{~N}_{4}$ 为催化剂 和可见光照射条件下, 白著芦醇 72 经 [3+2]环加成反应 实现了 Resveratrol 二聚体的合成. 该方法无金属参与, 利用可见光照射和氧化剂达到了高效且环境友好的目 的. 这也是非均相光催化首次用于该类氧化反应.

3',4-di-O-methylcedrusin 是从巴豆的皮层中分离得 到的一种新木脂烷类天然产物分子 ${ }^{[25 a]}$, 具有广谱的生 物活性. 2020 年, 汪义丰课题组 ${ }^{[25 b]}$ 发展了电催化的苯酚 与缺电子烯烃之间的氧化 $[3+2]$ 环加成反应, 并将该方 法应用于 3',4-di-O-methylcedrusin 的合成(Scheme 20).

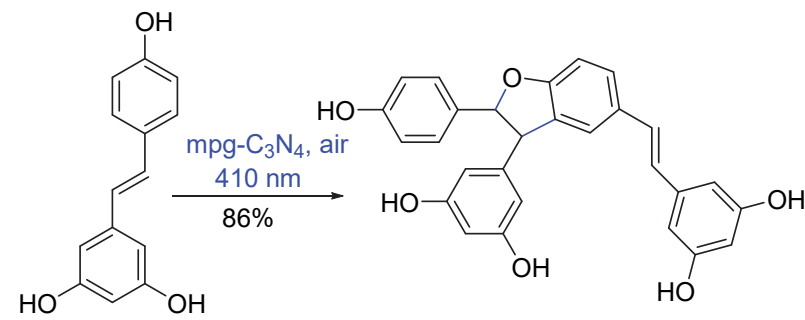

Resveratrol (72)

图式 19 刘强小组对 Resveratrol二聚体的合成 Scheme 19 Total synthesis of the dimer of Resveratrol by Liu's group

他们以廉价易得的邻甲氧基苯酚衍生物 87 与不饱和酯 88 为起始原料, 在六氟异丙醇和二氯甲烷的混合溶剂 中, 经电催化的环化反应, 以 $42 \%$ 的收率得到呋喃环化 合物 89, 随后再经氢化铝锂还原, 从而实现 3',4-di- $O$ methylcedrusin (90)的合成.

自然界存在众多具有二氢苯并呋喃骨架结构的手 性天然产物和药物，因此，实现该结构单元的非对映体 和对映选择性控制显得格外重要. 2006 年, Rindone 课题 组 ${ }^{[26]}$ 通过手性辅基诱导的不对称氧化 $[3+2]$ 环加成反 应，完成了脱氢双松柏醇(94)及相关天然产物的对映多 样性合成(Scheme 21). 他们以商业可得的阿魏酸 91 为<smiles>CCOC(=O)/C=C/c1ccc(OC)c(OC)c1</smiles>

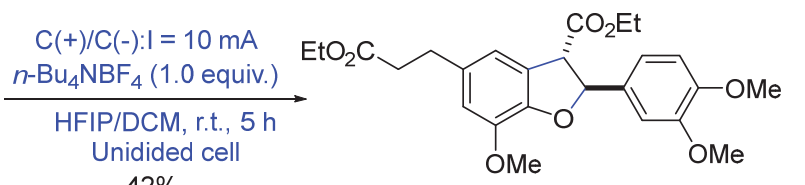

89<smiles>COc1ccc(C2Oc3c(OC)cc(CCCO)cc3[C@@H]2CO)cc1OC</smiles>

3',4-di-O-methylcedrusin (90)

图式 20 汪义丰小组对 3',4-di- $O$-methylcedrusin 的合成 Scheme 20 Synthesis of 3',4-di- $O$-methylcedrusin by Wang's group

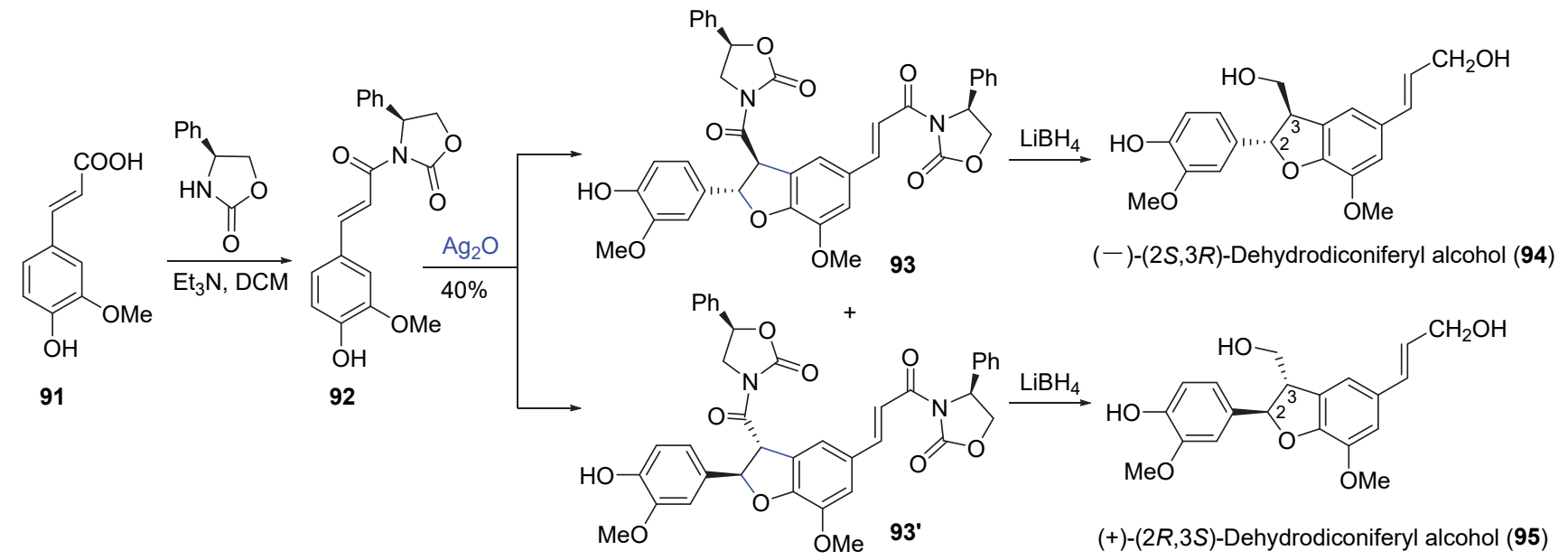

图式 21 Rindone 小组对脱氢双松柏醇的全合成

Scheme 21 Total synthesis of dehydrobisconiferyl alcohol by Rindone's group 
起始原料, 与手性噁唑烷酮经酰胺化反应得到环化前体 化合物 92. 随后在二氯甲烷溶剂中, 两分子环化前体 92 在氧化银条件下, 发生氧化 $[3+2]$ 环加成反应, 以 $40 \%$ 的产率得到二氢苯并呋喃环化合物 93 和 93 '. 它们再分 别经 $\mathrm{LiBH}_{4}$ 还原, 从而实现脱氢双松柏醇(94)和其对映 异构体(95)的合成.

2021 年, 涂永强团队 ${ }^{[27]}$ 发展了催化不对称的 [3+2] 环加成反应制备手性 2-芳基-2,3-二氢苯并呋喃骨架新 方法, 并将其应用于 Corsifurans A 和 B 的不对称合成 (Scheme 22). 他们将醌化合物 96 和对甲氧基苯乙烯 97 在甲苯溶剂中, 经 $\mathrm{Cu}(\mathrm{II})$ /螺吡咯烷(SPDO)复合体系催 化, 其中螺吡咯烷 (SPDO) 手性配体为该课题组近年来 发展的新型小分子不对称催化剂. 以 $86 \%$ 产率和高选择 性(ee 98\%)合成了二氢苯并呋喃化合物 98, 随后经水解 和脱羒以 $60 \%$ 的产率得到 Corsifuran B (99), 该化合物 再发生羟甲基化反应得到 Corsifuran A (100).

\section{4 氧化[3+2]环加成反应在黄酮合成中的应用}

紫檀烷(Pterocarpans, 103) 是植物被真菌感染后生 成的异黄酮类天然产物, 它具有抗肿瘤及抗 HIV 等多种 活性, 且其具有二氢苯并呋喃一苯并吡喃环四环骨架. 2009 年, Morrow 课题组 ${ }^{[28]}$ 报道了高价碘氧化的环加成 反应, 高效合成了紫檀烷 103 和 5-carbapterocarpan (104). 在乙腈溶剂中, 4-甲氧基苯酚(101)和烯烃化合物 102 在双三氟乙酰基碘苯(PIFA)为氧化剂的条件下, 以 较高产率得到两种苯并呋喃类骨架化合物. 该课题组对
酚和烯烃的范围都做了大量拓展，并合成了多个紫檀烷 类衍生物(Scheme 23).

2,3-Dihydrocalodenin B 是从非洲蕨类中分离的黄 酮类天然产物, 具有抗真菌、抗增殖和乳腺癌细胞毒性 等活性. 2015 年, Pappo 课题组 ${ }^{[29]}$ 在研究铁催化苯酚和 二酮类化合物的氧化交叉偶联效率和选择性时, 设计了 简洁的路线, 完成了 2"'-Dehydroxycalodenin B 的全合成 (Scheme 24). 他们以商业可得的间苯三酚衍生物 105 和 苯二酮 106 为起始原料, 以三氟乙醇(TFE)/二氯乙烷 (DCE)为混合溶剂, 在 $\mathrm{Fe}\left(\mathrm{ClO}_{4}\right)_{3}$ 水合物催化下发生氧化 $[3+2]$ 环加成反应，以 $40 \%$ 的产率得到呋喃环化合物 107, 随后再经过羟甲基化反应等三步转化，从而实现 了 2 "'-Dehydroxy-calodenin B (108)的合成.

\section{5 总结与展望}

迄今为止，苯酚和烯烃的氧化 $[3+2]$ 环加成反应在 多种天然产物分子如生物碱、萜类、木脂素以及黄酮等 的全合成过程中都得到了应用(Scheme 25). 在具体的 研究工作中, 既有 $\mathrm{PhI}(\mathrm{OAc})_{2}$ 等常见氧化剂的使用, 也 有光催化和电催化等新方法的发展, 同时也出现了少量 催化不对称的合成方法. 但就目前所报道的以该反应为 关键步骤的合成效率而论, 仍然有待提高. 尤其是不对 称 $[3+2]$ 环加成反应有很大提升空间, 应用和发展此反 应构建更多天然产物的苯并呋喃结构单元，也值得不断 探索和深入推进.

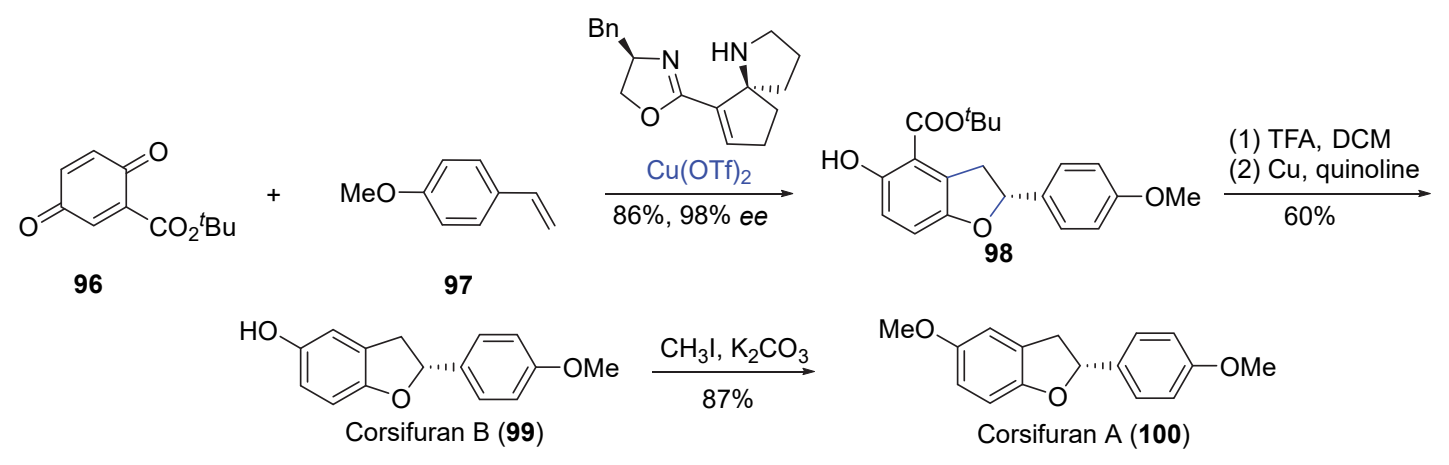

图式 22 涂永强小组对 Corsifurans A 和 B 的合成

Scheme 22 Synthesis of Corsifurans A and B by Tu's group

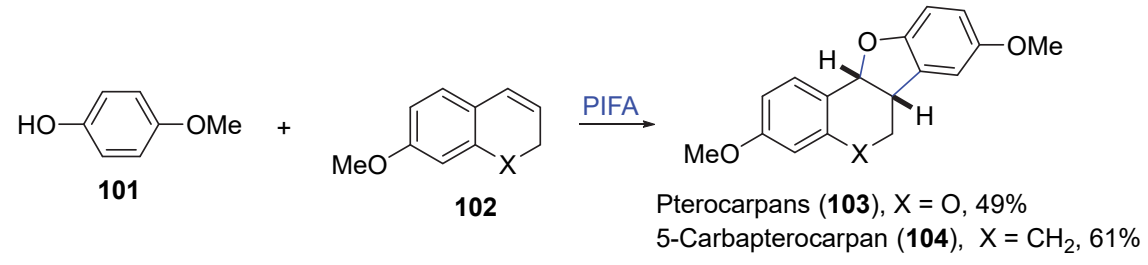

图式 23 Morrow 小组对 5-carbapterocarpan 和紫檀烷的合成

Scheme 23 Synthesis of 5-carbapterocarpan and pterocarpans by Morrow's group 
<smiles>COc1ccc(C(=O)CC(=O)c2ccc(OC)cc2)cc1</smiles>

图式 24 Pappo 小组对 2"'-dehydroxycalodenin B 的合成

Scheme 24 Synthesis of 2"'-dehydroxycalodenin B by Pappo's group<smiles>O=C1NCCc2c[nH]c3ccc(O)c(c23)[C@H]1c1ccc2c(c1)OCO2</smiles>

(+)-Decursivine (1)

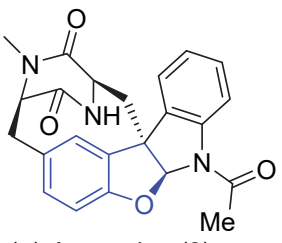

(+)-Azonazine (2)<smiles>COc1ccc2c(c1)OC[C@H]1c3cc(OC)ccc3O[C@@H]1c1cc(OC)ccc1-2</smiles>

Terpenes<smiles>CC(C)=CCC[C@H]1OC2=C(Cl)C(=O)c3c(O)cc(O)cc3[C@@]23CC(=C(C)O)C[C@@H]13</smiles>

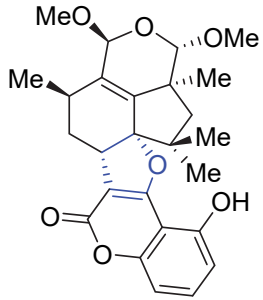

Hypocrolide A (60)

图式 25 应用氧化 $[3+2]$ 环加成反应合成天然产物一览

Scheme 25 Natural products synthesis via oxidative [3+2] cycloaddition

\section{References}

[1] Zhang, H.; Qiu, S.; Tamez, P.; Tan, G. T.; Aydogmus, Z.; Hung, N. V.; Cuong, N. M.; Angerhofer, C.; Soejarto, D. D.; Pezzuto, J. M.; Fong, H. H. S. Pharm. Biol. 2002, 40, 221.

[2] Wu, Q. X.; Crews, M. S.; Draskovic, M.; Sohn, J.; Johnson, T. A.; Tenney, K.; Valeriote, F. A.; Yao, X. J.; Bjeldanes, L. F.; Crews, P. Org. Lett. 2010, 12, 4458.

[3] (a) Liu, H.-X.; Chen, K.; Liu, Y.; Liu, C.; Wu, J.-W.; Xu, Z.-F.; Tan, H.-B.; Qiu, S.-X. Fitoterapia 2016, 115, 142

(b) Cao, J.-Q.; Tian, H.-Y.; Li, M.-M.; Zhang, W.; Wang, Y.; Wang, L.; Ye, W.-C. J. Nat. Prod. 2018, 81, 57.

(c) Wu, L.; Zhang, Y.-L.; Wang, X.-B.; Zhang, Y.-M.; Yang, M.-H.; Luo, J.; Kong, L.-Y. Tetrahedron 2017, 73, 1105.

[4] Laurita, T.; D’Orsi, R.; Chiummiento, L.; Funicello, M.; Lupattelli, P. Synthesis 2020, 52, 1451 .

[5] Cui, N.; Zhao, Y.; Wang, Y. Chin. J. Org. Chem. 2017, 37, 20 (in Chinese).

(崔娜, 赵宇, 王云侠, 有机化学, 2017, 37, 20.)

[6] Dohi, T.; Toyoda, Y.; Nakae, T.; Koseki, D.; Kubo, H.; Kamitanaka, T.; Kita, Y. Heterocycles 2015, 90, 631.

[7] Chen, Z.; Pitchakuntla, M.; Jia, Y. Nat. Prod. Rep. 2019, 36, 666.

[8] (a) Lindquist, N.; Fenical, W.; Van Duyne, G. D.; Clardy, J. J. Am. Chem. Soc. 1991, 113, 2303.

(b) Burgett, A. W. G.; Li, Q. Y.; Wei, Q.; Harran, P. G. Angew. Chem., Int. Ed. 2003, 42, 4961.

[9] Zhao, J.-C.; Yu, S.-M.; Liu, Y.; Yao, Z.-J. Org. Lett. 2013, 15, 4300.
[10] (a) Anderton, N.; Cockrum, P. A.; Colegate, S. M.; Edgar, J. A.; Flower, K.; Gardner, D.; Willing, R. I. Phytochemistry 1999, 51, 153.

(b) Tomakinian, T.; Guillot, R.; Kouklovsky, C.; Vincent, G. Angew Chem., Int. Ed. 2014, 53, 11881.

[11] Li, L.; Yuan, K.; Jia, Q.; Jia, Y. Angew. Chem., Int. Ed. 2019, 58, 6074.

[12] (a) Rogers, E. F.; Snyder, H. R.; Fischer, R. F. J. Am. Chem. Soc. 1952, 74, 1987.

(b) Nicolaou, K. C.; Dalby, S. M.; Li, S.; Suzuki, T.; Chen, D. Y.-K. Angew. Chem., Int. Ed. 2009, 48, 7616.

[13] Sun, D.; Zhao, Q.; Li, C. Org. Lett. 2011, 13, 5302.

[14] Liang, K.; Yang, J.; Tong, X.; Shang, W.; Pan, Z.; Xia, C. Org. Lett. 2016, $18,1474$.

[15] (a) Sato, H.; Kawagishi, H.; Nishimura, T.; Yoneyama, S.; Yoshimoto, Y.; Sakamura, S.; Furusaki, A.; Katsuragi, S.; Matsumoto, T. Agric. Biol. Chem. 1985, 49, 2969.

(b) Liang, K.; Wu, T.; Xia, C. Org. Biomol. Chem. 2016, 14, 4690.

[16] (a) Sakoulas, G.; Nam, S.-J.; Loesgen, S.; Fenical, W.; Jensen, P. R.; Nizet, V.; Hensler, M. PLoS One 2012, 7, e29439.

(b) Meier, R.; Strych, S.; Trauner, D. Org. Lett. 2014, 16, 2634.

[17] (a) Yuan, Y. F.; Feng, Y.; Ren, F. X.; Niu, S. B.; Liu, X. Z.; Che, Y. S. Org. Lett. 2013, 15, 6050.

(b) Qiao, C.; Zhang, W.; Han, J.-C.; Li, C.-C. Org. Lett. 2016, 18, 4932.

[18] Guo, Y.; Zhang, Y.; Xiao, M.; Xie, Z. Org. Lett. 2018, 20, 2509.

[19] Dethe, D. H.; Nirpal, A. K. Org. Biomol. Chem. 2019, 17, 7507. 
[20] (a) Langcake, P.; Pryce, R. J. Experientia 1977, 33, 151. (b) Sako, M.; Hosokawa, H.; Ito, T.; Iinuma, M. J. Org. Chem. 2004, 69, 2598

[21] (a) Hada, S.; Hattori, M.; Tezuka, Y.; Kikuchi, T.; Namba, T. Phytochemistry 1988, 27, 563 .

(b) Hattori, M.; Yang, X.-W.; Shu, Y.-Z.; Kakiuchi, N.; Tezuka, Y.; Kikuchi, T.; Namba, T. Chem. Pharm. Bull. 1988, 36, 648.

(c) Juhász, L.; Kürti, L.; Antus, S. J. Nat. Prod. 2000, 63, 866.

[22] (a) Doskotch, R. W.; Flom, M. S. Tetrahedron 1972, 28, 4711.

(b) Chen, P.-Y.; Wu, Y.-H.; Hsu, M.-H.; Wang, T.-P.; Wang, E.-C. Tetrahedron, 2013, 69, 653.

[23] Blum, T. R.; Zhu, Y.; Nordeen, S. A.; Yoon, T. P. Angew. Chem., Int. Ed. 2014, 53, 11056.

[24] Song, T.; Zhou, B.; Peng, G.-W.; Zhang, Q.-B.; Wu, L. Z.; Liu, Q.;
Wang, Y. Chem.-Eur. J. 2014, 20, 678.

[25] (a) Pieters, L.; De Bruyne, T.; Claeys, M.; Vlietinck, A.; M. Calommeand, M.; vanden Berghe, D. J. Nat. Prod. 1993, 56, 899.

(b) Zhao, Q.; Jin, J.-K.; Wang, J.; Zhang, F.-L.; Wang, Y.-F. Chem. Sci. 2020, 11, 3909.

[26] Bruschi, M.; Orlandi, M.; Rindone, B.; Rummakko, P.; Zoia, L. J. Phys. Org. Chem. 2006, 19, 592.

[27] Jing, Z.-R.; Liang, D.-D.; Tian, J.-M.; Zhang, F.-M.; Tu, Y.-Q. Org. Lett. 2021, 23, 1258.

[28] Mohr, A. L.; Lombardo, V. M.; Arisco, T. M.; Morrow, G. W. Synth. Commun. 2009, 39, 3845.

[29] Gaster, E.; Vainer, Y.; Regev, A.; Narute, S.; Sudheendran, K.; Werbeloff, A.; Shalit, H.; Pappo, D. Angew. Chem., Int. Ed. 2015, 54,4198 .

(Zhao, C.) 